For the Supporting Information of

\title{
Improved Sensitivity of Intramolecular Strand Displacement Based on Localization of Probes
}

\author{
Seung Won Shin,,$^{\dagger, \perp}$ So Yeon Ahn, ${ }^{\dagger}, \perp$ Yong Taik Lim, ${ }^{\dagger, \dagger}$ and Soong Ho Um ${ }^{*}, \dagger,+$ \\ †School of Chemical Engineering, Sungkyunkwan University, Suwon, Gyeonggi-do 16419, South Korea \\ *SKKU Advanced Institute of Nanotechnology (SAINT), Sungkyunkwan University, Suwon, Gyeonggi-d \\ o 16419, South Korea \\ *To whom correspondence should be addressed: sh.um@skku.edu \\ ${ }^{\perp}$ These authors contributed equally.
}

\section{Table of Contents}

Table S1. $\quad$ Sequences of strands comprising DNA nanostructures.

Figure S1. Gel electrophoresis analysis of (a) D-DNA (b) T-DNA (c) Y-DNA (d) H-DNA fabrication.

Section 1. Characterization of probe hybridization induced by miR-21.

Figure S2. Theoretical background for $\beta$ form DNA nanostructure preparation.

Figure S3. The reaction kinetics of $\mathrm{H} 1$ and $\mathrm{H} 2$ hybridization in DNA nanostructures.

Section 2. Determination of limit of detection and curve fitting.

Section 3. Smoluchowski coagulation model for the calculation of collision frequency.

Table S2. Collision frequencies of intermolecular and intramolecular interactions between $\mathrm{H} 1$ and $\mathrm{H} 2$ on free-H1/H2 and DNA nanostructures.

Table S3. Input parameters for oxDNA simulation and conditions for initial structure generation and analysis.

Figure S4. Mutual trap applying base pair information (red boxes) and standard base for measurement of distance between $\mathrm{H} 1$ and $\mathrm{H} 2$ (blue boxes) in (a) D-DNA (b) T-DNA (c) H-DNA.

Figure S5. Graphical representation of (a) D-DNA (b) T-DNA (c) H-DNA generated by oxDNA.

Figure S6. Statistical validation of low LoD of 2-Arm T-DNA.

Visual aids of graphically reconstructed molecular movement of DNA nanostructures at every 3.03 fs time interval through oxDNA (AVI file separately uploaded). 
Table S1. Sequences of strands comprising DNA nanostructures

\begin{tabular}{ccl}
\hline DNA nanostructure composing strand & \\
\hline H1 & H1 & $\begin{array}{l}\text { 5'- TCA ACA TCA GTC TGA TAA GCT ACC ATG TGT AGA TAG CTT } \\
\text { ATC AGA CI -3' }\end{array}$ \\
H2 & H2 & $\begin{array}{l}\text { 5'- TAA GCT ATC TAC ACA TGG TAG CTT ATC AGA CTC CAT GTG TAG } \\
\text { A-3' }\end{array}$
\end{tabular}
$\begin{array}{ll} & \text { 5'- CGA CCG ATG AAT AGC GGT CAG ATC CGT ACC TAC TCG TCA } \\ \text { S1-H1 } & \text { ACA TCA GTC TGA TAA GCT ACC ATG TGT AGA TAG CTT ATC AGA }\end{array}$ CI- $3^{\prime}$

D-DNA

$\begin{array}{ll}\text { 58-H2 } & \text { 5GA GTA GGT ACG GAT CTG ACC GCT ATT CAT CGG TCG TAA } \\ \text { GCT ATC TAC ACA TGG TAG CTT ATC AGA CTC CAT GTG TAG A -3' }\end{array}$

51-H1 5'- CGA CCG ATG AAT AGC GGT CAG ATC CGT ACC TAC TCG TCA ACA TCA GTC TGA TAA GCT ACC ATG TGT AGA TAG CTT ATC AGA

CI- $3^{\prime}$

$\begin{array}{ll}\text { 52-H2 } & \text { CGA GTA GGT ACG GAT CTG CGT ATT GCG AAC GAC TCG TAA } \\ \text { GCT ATC TAC ACA TGG TAG CTT ATC AGA CTC CAT GTG TAG A -3' }\end{array}$

T-DNA

S3-H1

5'- CGA GTC GTT CGC AAT ACG GCT GTA CGT ATG GTC TCG TCA ACA TCA GTC TGA TAA GCT ACC ATG TGT AGA TAG CTT ATC AGA $\mathrm{C} \boldsymbol{- 1} \mathbf{3}^{\prime}$

S4-H2

5'- CGA GAC CAT ACG TAC AGC ACC GCT ATT CAT CGG TCG TAA GCT ATC TAC ACA TGG TAG CTT ATC AGA CTC CAT GTG TAG A -3' 
5'- CGA CCG ATG AAT AGC GGT CAG ATC CGT ACC TAC TCG TCA ACA TCA GTC TGA TAA GCT ACC ATG TGT AGA TAG CTT ATC AGA CII- $3^{\prime}$

5'- CGA GTA GGT ACG GAT CTG CGT ATT GCG AAC GAC TCG TAA GCT ATC TAC ACA TGG TAG CTT ATC AGA CTC CAT GTG TAG A -3'

5'- CGA GTC GTT CGC AAT ACG GCT GTA CGT ATG GTC TCG TCA CI- $3^{\prime}$ '

H-DNA

S5-H2 5'- CGA GAC CAT ACG TAC AGC GCG ATG CGC ACG CGC ACG TAA GCT ATC TAC ACA TGG TAG CTT ATC AGA CTC CAT GTG TAG A -3'

5'- CGT GCG CGT GCG CAT CGC TGC GGT GCC GTG TGC ACG TCA ACA TCA GTC TGA TAA GCT ACC ATG TGT AGA TAG CTT ATC AGA CП-3'

S7-H2 5'- CGT GCA CAC GGC ACC GCA ACC GCT ATT CAT CGG TCG TAA GCT ATC TAC ACA TGG TAG CTT ATC AGA CTC CAT GTG TAG A -3'

Y-DNA

5'- CGA CCG ATG AAT AGC GGT CAG ATC CGT ACC TAC TCG TCA ACA TCA GTC TGA TAA GCT ACC ATG TGT AGA TAG CTT ATC AGA CI- $3^{\prime}$ GCT ATC TAC ACA TGG TAG CTT ATC AGA CTC CAT GTG TAG A -3' 
5'- CGA CCG ATG AAT AGC GGT CAG ATC CGT ACC TAC TCG TCA ACA TCA GTC TGA TAA GCT ACC ATG TGT AGA TAG CTT ATC AGA Cा - $3^{\prime}$

Red highlights indicate the location of Cy5 fluorophore and blue indicate the Iowa Black® dark quencher. 

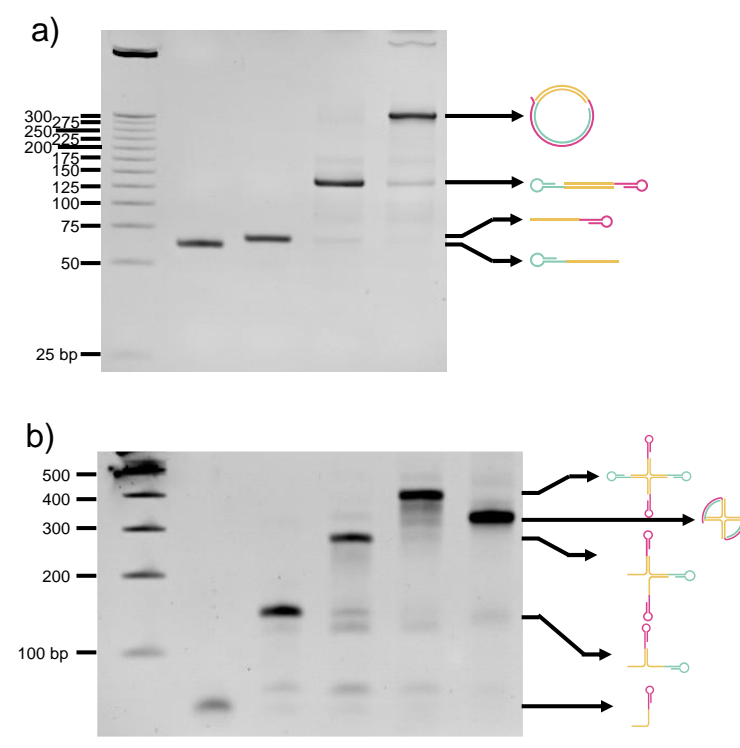

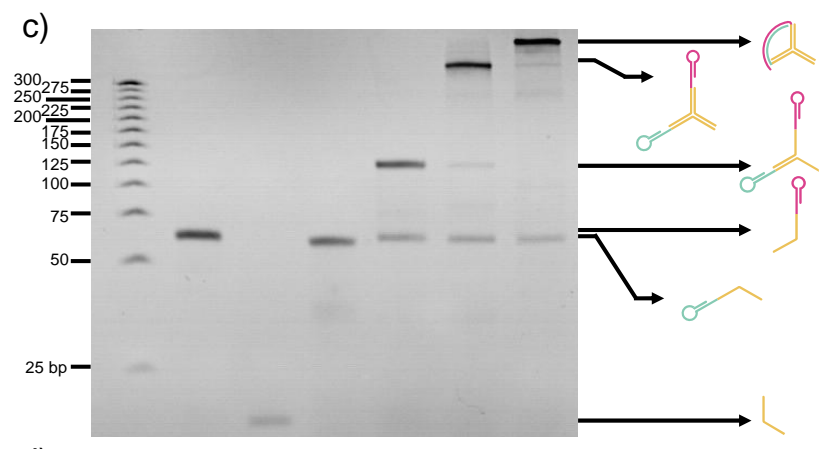

d)

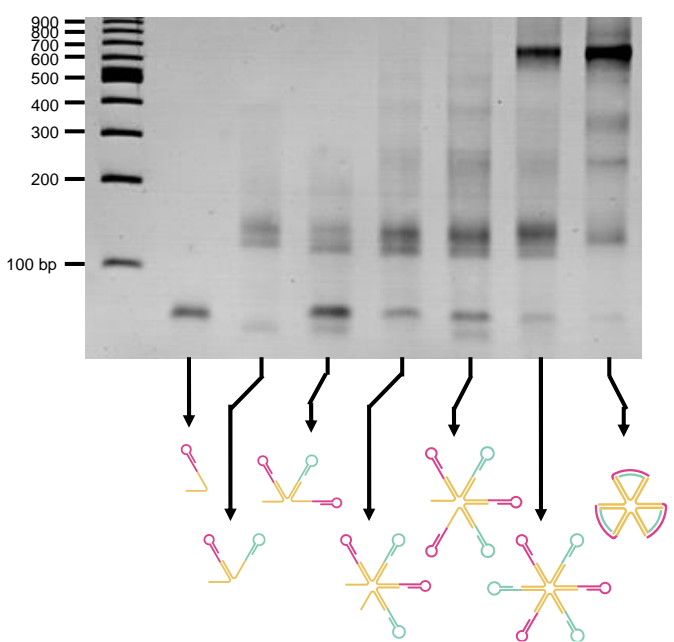

Figure S1. Gel electrophoresis analysis of fabrication of (a) D-DNA (b) T-DNA (c) Y-DNA (d) H-DNA.

All the oligonucleotides used in the experiments were purchased from Integrated DNA Technologies. The sequence information of the oligonucleotides is noted in Table S1. The oligonucleotides were dissolved in Tris-EDTA buffer $(\mathrm{pH} 7.5)$ at a $100 \mu \mathrm{M}$ concentration before DNA nanostructure assembly. D-DNA, T-DNA, H-DNA, Y-DNA, and 2-Arm T-DNA were fabricated through dual annealing to avoid unwanted hybridization between $\mathrm{H} 1$ and $\mathrm{H} 2$ during DNA nanostructure preparation. Dual annealing consisted of two steps. The first step individually annealed the composing strands of DNA nanostructures to successfully form hairpin structures of $\mathrm{H} 1$ and $\mathrm{H} 2$ motifs (pre-annealing), and the second step used lowtemperature annealing to assemble scaffolding structures without deformation of the hairpin structures. Each component strand of H1/H2, D-DNA, T-DNA, H-DNA, Y-DNA, and 2-Arm T-DNA was individually annealed from 95 to $4{ }^{\circ} \mathrm{C}$ at a rate of $-0.5^{\circ} \mathrm{C} / 30 \mathrm{~s}$ with concentrations of $300 \mathrm{nM}, 600 \mathrm{nM}, 1200 \mathrm{nM}, 1800 \mathrm{nM}, 900 \mathrm{nM}$, and $1200 \mathrm{nM}$, respectively. The $\mathrm{NaCl}$ concentration was adjusted to $200 \mathrm{mM}$ for all annealing procedures. After annealing, equivalent volumes of all component strand solutions of DNA nanostructures were mixed and annealed from 43.5 to $4{ }^{\circ} \mathrm{C}$ at a rate of $-0.5{ }^{\circ} \mathrm{C} / 30 \mathrm{~s}$. In the case of $\mathrm{H}$-DNA, the annealing temperature was adjusted from 55 to $4{ }^{\circ} \mathrm{C}$ at a rate of $-0.1{ }^{\circ} \mathrm{C} / 144 \mathrm{~s}$. Finally, the fabricated DNA nanostructures were adjusted to $300 \mathrm{nM}$ and stored at $4{ }^{\circ} \mathrm{C}$ until further usage. 
Section 1. Characterization of probe hybridization induced by miR-21.

The concentrations of $\mathrm{H} 1$ and $\mathrm{H} 2$ were adjusted to $100 \mathrm{nM}$ in all experiments without specification; accordingly, the concentrations of the DNA nanostructures differed (concentrations of D-DNA, T-DNA, H-DNA, Y-DNA, and 2- Arm T-DNA were $100 \mathrm{nM}, 50$ $\mathrm{nM}, 33.3 \mathrm{nM}, 100 \mathrm{nM}$, and $100 \mathrm{nM}$, respectively). The reaction temperature and $\mathrm{NaCl}$ concentration were maintained at $37^{\circ} \mathrm{C}$ and $150 \mathrm{mM}$. DNA nanostructures were analyzed by polyacrylamide gel, $12 \%$ for D-DNA and Y-DNA and $5 \%$ for T-DNA and H-DNA, electrophoresis. (Figure 2b) After electrophoresis, the gel was stained with $0.5 \mu \mathrm{g} / \mathrm{mL}$ ethidium bromide solution for visualization. For detailed access to the reaction progress of the hybridization kinetics, a Förster resonance energy transfer (FRET) system was used. Cy5 fluorescent dye was used as a fluorophore and attached to the $5^{\prime}$ end of $\mathrm{H} 1$ to recover fluorescence by moving away from the Iowa Black ${ }^{\circledR}$ dark quencher after hybridization with miR-21. Fluorescence intensity was measured with a spectrophotometer (SpectraMax M5, Molecular Devices, Sunnyvale, CA). The Cy5 dye was excited with a $640 \mathrm{~nm}$ wavelength laser, and the emission was measured at a wavelength of $670 \mathrm{~nm}$. The fraction of $\mathrm{H} 1 / \mathrm{H} 2$ hybridization was calculated with below formula.

$$
\text { Fraction of } H 1 / H 2 \text { hybridization }=\frac{\text { Fluoresence intensity }}{\text { Fluorescence intensity of } \beta \text { form }}
$$

Since the $\beta$ form of DNA nanostructure has fully hybridized $\mathrm{H} 1$ and $\mathrm{H} 2$, theoretically, the fluorescence intensity from FRET shows the highest fluorescence intensity. Therefore, the fraction of intramolecular hybridization could be calculated by dividing the measured fluorescence intensity by the fluorescence intensity of $\beta$ form. 

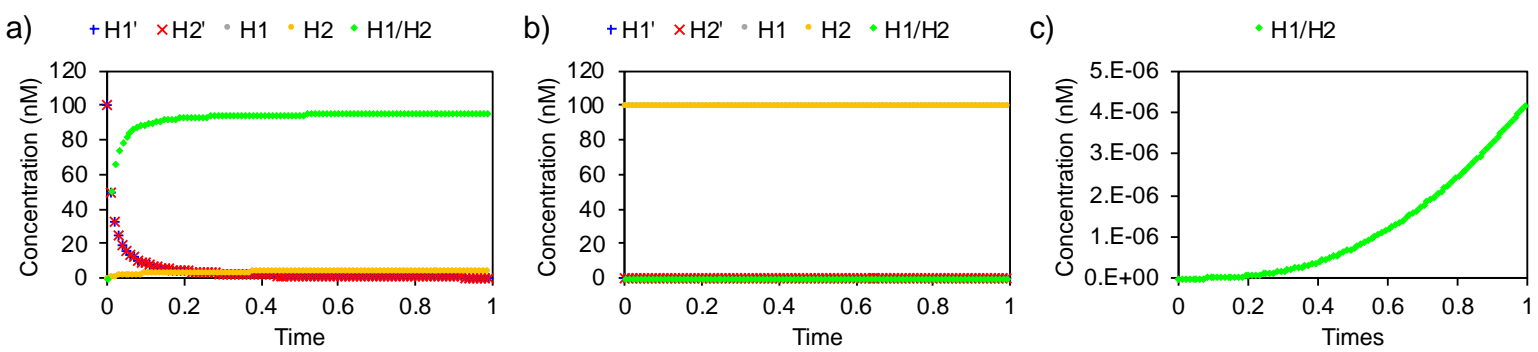

Figure S2. Theoretical background for $\beta$ form DNA nanostructure preparation.

As described in Figure S1, unreacted products of $\mathrm{H} 1$ and $\mathrm{H} 2$ in DNA nanostructures were prepared with pre-annealing of $\mathrm{H} 1$ and $\mathrm{H} 2$ strands. In contrast, DNA nanostructures with maximized intramolecular hybridization reactions of $\mathrm{H} 1$ and $\mathrm{H} 2$ were prepared without preannealing. Reactant concentrations and theoretical kinetics with and without pre-annealing were discussed below.

Elementary reactions involved in hybridization of $\mathrm{H} 1$ and $\mathrm{H} 2$ are as follows:

$\mathrm{H} 1^{\prime} \rightleftharpoons \mathrm{H} 1$

$$
\Delta \mathrm{G}_{1}^{\circ}=-9.54 \mathrm{kcal} / \mathrm{mole}
$$

$\mathrm{H} 2^{\prime} \rightleftharpoons \mathrm{H} 2$

$\Delta \mathrm{G}_{2}^{\circ}=-7.59 \mathrm{kcal} / \mathrm{mole}$

$\mathrm{H} 1^{\prime}+\mathrm{H} 2^{\prime} \rightleftharpoons \mathrm{H} 1 / \mathrm{H} 2$

$$
\Delta \mathrm{G}_{H}^{\circ}=-51.56 \mathrm{kcal} / \mathrm{mole}
$$

In the reaction equation, $\mathrm{H}^{\prime}{ }^{\prime}, \mathrm{H} 2^{\prime}$ indicate single stranded $\mathrm{H} 1$ and $\mathrm{H} 2 ; \mathrm{H} 1, \mathrm{H} 2$ indicate $\mathrm{H} 1$ and $\mathrm{H} 2$ in hairpin structure; $\mathrm{H} 1 / \mathrm{H} 2$ indicates hybridized $\mathrm{H} 1$ and $\mathrm{H} 2$. The other possible structures have significantly unstable Gibbs free energy and were removed to simplify the calculation. Mass balance of each reaction is as follows:

$$
\begin{aligned}
& \frac{d C_{H 1}}{d t}=k_{f 1} C_{H 1},-k_{b 1} C_{H 1}-k_{b H} C_{H 1 / H 2} \\
& \frac{d C_{H 2}}{d t}=k_{f 2} C_{H 2},-k_{b 2} C_{H 2}-k_{b H} C_{H 1 / H 2} \\
& \frac{d C_{H 1 / H 2}}{d t}=k_{f H} C_{H 1} C_{H 2}-k_{b H} C_{H 1 / H 2} \\
& K_{1}^{e q}=\frac{k_{f 1}}{k_{b 1}} \quad K_{2}^{e q}=\frac{k_{f 2}}{k_{b 2}} \quad K_{H}^{e q}=\frac{k_{f H}}{k_{b H}} \quad K^{e q}=e^{-\frac{\Delta G}{R T}}
\end{aligned}
$$

Assuming $k_{f 1}=k_{f 2}=k_{f H}=k_{f}$, mass balance can be written as following:

$$
\begin{aligned}
& \frac{d C_{H 1}}{d t}=k_{f}\left(C_{H 1^{\prime}}-\frac{1}{K_{1}^{e q}} C_{H 1}-\frac{1}{K_{H}^{e q}} C_{H 1 / H 2}\right) \\
& \frac{d C_{H 2}}{d t}=k_{f}\left(C_{H 2^{\prime}}-\frac{1}{K_{2}^{e q}} C_{H 2}-\frac{1}{K_{H}^{e q}} C_{\frac{H 1}{H 2}}\right)
\end{aligned}
$$




$$
\frac{d C_{H 1 / H 2}}{d t}=k_{f}\left(C_{H 1^{\prime}} C_{H 2^{\prime}}-\frac{1}{K_{H}^{e q}} C_{H 1 / H 2}\right)
$$

Based on the above equation, ordinary differential equation applied to calculate the theoretical concentrations of reactants over time. Pre-annealing of single strands leads to the formation of the hairpin structures of $\mathrm{H} 1$ and $\mathrm{H} 2$ first. The initial reactant concentration with or without preannealing can be expressed as follows.

$$
\begin{array}{ll}
\text { With pre-annealing: } & \mathrm{H} 1(100 \mathrm{nM}), \mathrm{H} 2(100 \mathrm{nM}) \\
\text { Without pre-annealing: } & \mathrm{H} 1^{\prime}(100 \mathrm{nM}), \mathrm{H} 2^{\prime}(100 \mathrm{nM})
\end{array}
$$

With the initial reactant concentrations, the reaction procedures were traced numerically. For the calculation arbitrary $k_{f}$ and $t$ were used, $\left(k_{f}=0.0001, t=10000\right)$, and the results were plotted as below.

Above Figure S2a shows the reaction progress of hybridization without pre-annealing. With the time goes, hybridized H1/H2 increased aggressively. Meanwhile, H1 and H2 increase relatively slowly and stagnate. This shows that when unstructured strands are present at the same time, there is a dominant fraction hybridized $\mathrm{H} 1 / \mathrm{H} 2$ forms ( $\beta$ form). In case of reaction progress with pre-annealing, $\mathrm{H} 1$ and $\mathrm{H} 2$ maintained their concentration for the same period of calculation. (Figure S2b) Since pre-annealing already provided a stable form of $\mathrm{H} 1$ and $\mathrm{H} 2$, it takes much longer for the reaction to proceed to hybridized $\mathrm{H} 1 / \mathrm{H} 2$. Of course, the $\mathrm{H} 1 / \mathrm{H} 2$ hybridization reaction proceeds despite the very low rate as shown in Figure S2c. 
Section 2. Determination of limit of detection and curve fitting.

LoDs of free-H1/H2 and DNA nanostructures were calculated according to the guideline from the Clinical and Laboratory Standard Institute per the following formula:

$$
\mathrm{LoD}=F_{\text {Blank }}+1.645 \times \sigma_{\text {Blank }}+1.645 \times \sigma_{\text {Low }}
$$

where $F_{\text {Blank }}$ is fluorescence intensity of blank, and $\sigma_{\text {Blank }}$ and $\sigma_{\text {Low }}$ are the standard deviation of the blank and low concentration samples, respectively. The blank and the low concentration samples correspond to samples with 0 and $10 \mathrm{nM}$ miR-21 concentrations, respectively. The equation of the fitting curve was a sigmoidal Weibull model $\left(R=\mathrm{a}-b e^{-c t^{d}}\right.$; $R$ : reaction degree, $\mathrm{t}$ : time, $\mathrm{a}, \mathrm{b}, \mathrm{c}, \mathrm{d}$ : arbitrary numbers). 

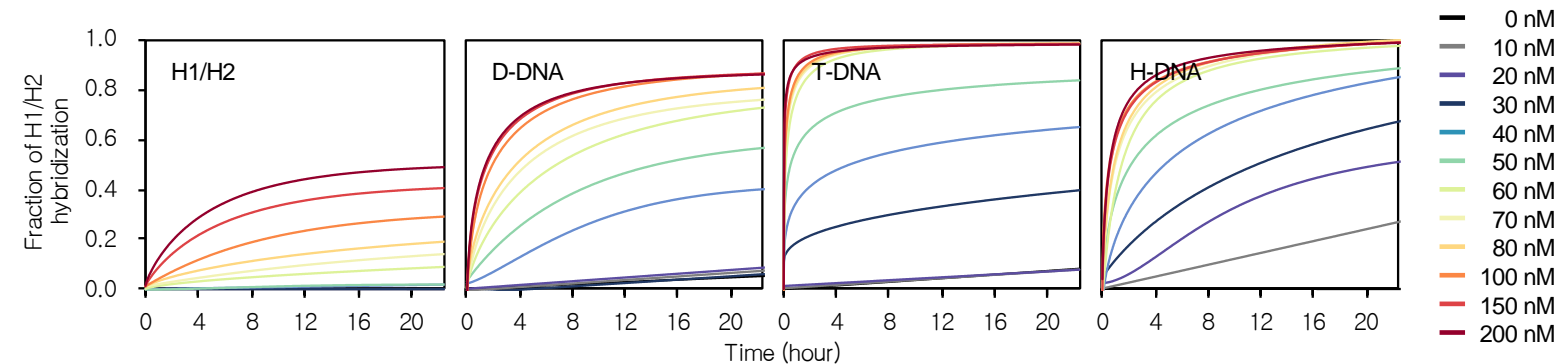

Figure S3. The reaction kinetics of $\mathrm{H} 1$ and $\mathrm{H} 2$ hybridization in DNA nanostructures. 
Section 3. Smoluchowski coagulation model for the calculation of collision frequency.

Collisions between $\mathrm{H} 1$ and miR-21 molecules, which correspond to intermolecular reaction in a solution, must occur as a first step in generation of a detection signal. As the collision frequency directly affects the reactivity of probes and sensitivity of the biosensor, intermolecular collision frequencies of free-H1/H2, D-DNA, T-DNA, and H-DNA were theoretically evaluated through application of the Smoluchowski coagulation model. The intermolecular collision frequencies between $\mathrm{H} 1$ and $\mathrm{H} 2$ of free-H1/H2, D-DNA, T-DNA, and H-DNA were theoretically evaluated through part of the Smoluchowski coagulation model. The flux $(F)$ of particles whose centers pass through a sphere of radius $(r)$ surrounding the central particle is given by Fick's law, where $R$ : the distance between centers of two colliding particles, in this case $2 r ; D$ : diffusivity; and $v_{0}$ : bulk concentration of the solute.

$$
F=4 \pi R D v_{0}
$$

Assuming similar radii of colliding particles, $D$ is given by the Einstein-Stokes equation, where $K_{B}$ : Boltzmann coefficient and $\eta$ : kinematic viscosity of the solution, $759.879 \mu \mathrm{Pa} \bullet$ s).

$$
D=\frac{2 K_{B} T}{3 \pi \eta R}
$$

By substituting equation (2) into (1), the flux $(F)$ can be expressed as follows:

$$
F=\frac{8 K_{B} T}{3 \eta} v_{0}
$$

the intermolecular collision frequency of each DNA nanostructure can be calculated. All constants other than $v_{0}$ were the same for every DNA nanostructure: $K_{B}=1.38 \times$ $10^{-23} \mathrm{~m}^{2} \cdot \mathrm{kg} \bullet \mathrm{s}^{-2} \mathrm{~K}^{-1}$ and $\eta=759.873 \times 10^{-6} \mathrm{~Pa} \bullet \mathrm{s}^{-1}$. To equalize the total numbers of $\mathrm{H} 1$ and $\mathrm{H} 2$, the $v_{0}$ values of DNA nanostructures were adjusted to $200 \mathrm{nM}, 100 \mathrm{nM}, 50 \mathrm{nM}$, and $33.3 \mathrm{nM}$ for free-H1/H2, D-DNA, T-DNA and H-DNA, respectively.

Calculation of intermolecular collision frequency of free- $\mathrm{H} 1 / \mathrm{H} 2$ is as follows:

$$
F=\frac{8 \times\left[1.38 \times 10^{-23} \mathrm{~m}^{2} \cdot \mathrm{kg} \cdot \mathrm{s}^{-2} \cdot \mathrm{K}^{-1}\right] \times[310.15 \mathrm{~K}]}{3 \times\left[759.873 \times 10^{-6} \mathrm{~Pa} \cdot \mathrm{s}^{-1}\right]} \times[200 \mathrm{nM}]=1808.4 \mathrm{~s}^{-1}
$$

This corresponds to a total frequency of collision one particle is experiencing at the given condition and it can also be calculated for D-DNA, T-DNA and H-DNA differing the $v_{0}$ values. Since this collision frequency does not consider the effectiveness of collision, the orientation of $\mathrm{H} 1$ and $\mathrm{H} 2$ moiety for actual reaction to occur, the probability of effective collision was assumed to be 0.5 in all cases based on composition and geometric probability of DNA nanostructures.

$$
\text { Effective collision frequency of free }-\mathrm{H} 1 / \mathrm{H} 2=1808.4 \mathrm{~s}^{-1} \times 0.5=904.2 \mathrm{~s}^{-1}
$$


Table S2. Collision frequencies of intermolecular and intramolecular interactions between $\mathrm{H} 1$ and $\mathrm{H} 2$ on free-H1/H2 and DNA nanostructures.

\begin{tabular}{ccccc}
\hline & Free-H1/H2 & D-DNA & T-DNA & H-DNA \\
\hline Concentration of H1, H2 motif $(\mathrm{nM})$ & 100 & 100 & 100 & 100 \\
Concentration of DNA nanostructures $(\mathrm{nM})$ & $\mathrm{N} / \mathrm{A}$ & 100 & 50 & 33.3 \\
Intermolecular Collision Frequency $\left(\mathrm{s}^{-1}\right)$ & $9.04 \times 10^{2}$ & $4.52 \times 10^{2}$ & $2.26 \times 10^{2}$ & $1.51 \times 10^{2}$ \\
Intramolecular Collision Frequency $\left(\mathrm{s}^{-1}\right)$ & $\mathrm{N} / \mathrm{A}$ & $1.51 \times 10^{4}$ & $2.92 \times 10^{5}$ & $1.69 \times 10^{6}$ \\
\hline
\end{tabular}

*N/A: Not available 
Table S3. Input parameters for oxDNA simulation and conditions for initial structure generation and analysis.

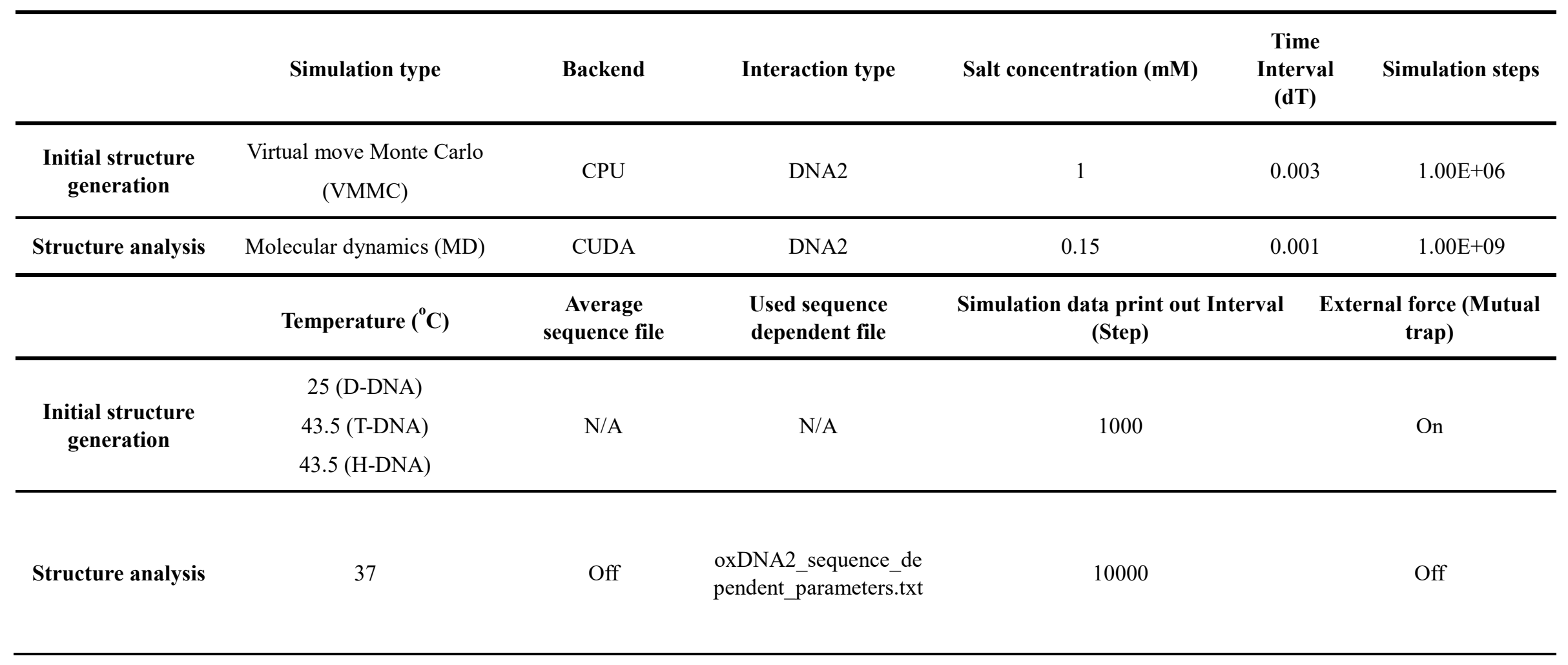

Structural analysis of D-DNA, T-DNA, and H-DNA was achieved with coarse-grained molecular dynamics simulation software, oxDNA. The analysis consisted of two successive steps: 1) an initial DNA nanostructure generation step and 2) a structural movement analysis step. The detailed simulation input parameters and conditions used for initial DNA structure preparation and structural movement analysis are noted in Table S2. Additional settings used default values. A "mutual trap" function was used to fabricate the basic structure of the DNA nanostructures using the oxDNA program. In our case, the second bases from each end of the complementary oligonucleotides were trapped together for rapid fabrication of the initial structure. For H-DNA, several additional bases were trapped together to avoid unwanted secondary structures. Trapped 
base pairs are noted by red boxes in Figure S4 for better visual comprehension. The graphical representations of generated DNA nanostructures are shown in Figure S5.

After each initial structure was generated as expected, the molecular behavior of the DNA nanostructures was simulated by sequence-dependent molecular dynamic conditions without mutual trapping. Movements of individual DNA nanostructures were measured for $3.03 \mu$ s with intervals of $3.03 \mathrm{fs}$. The distance from the eighth base from the $3^{\prime}$ end of $\mathrm{H} 1$ to the first base from the $5^{\prime}$ end of $\mathrm{H} 2$ was measured in each simulation step and used for collision frequency estimation. When the distances between $\mathrm{H} 1$ and $\mathrm{H} 2$ reached 1 simulation length unit, a collision was considered. The general criterion of effective collision in oxDNA was 1 oxDNA length unit, equivalent to $0.8518 \mathrm{~nm}$. According to measured intramolecular distances between $\mathrm{H} 1$ and $\mathrm{H} 2$, the intramolecular collision frequency of probes in DNA nanostructure was estimated. The counts were calculated when the distance was exceeding 1 oxDNA length unit in the previous simulation step and the distance was less than 1 oxDNA length unit in the subsequent step. The calculated counts were then divided by the total simulation time to estimate the collision frequency 
AGAC $C$ S1 H1 作

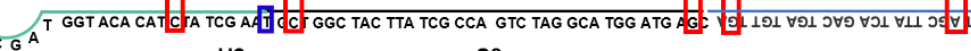

b

H2

S8

miR-21

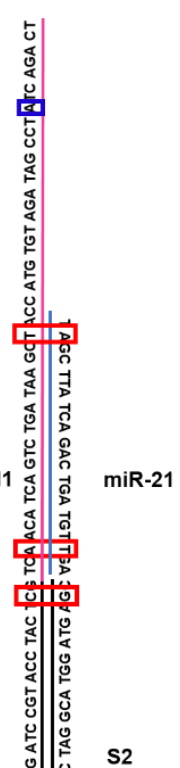

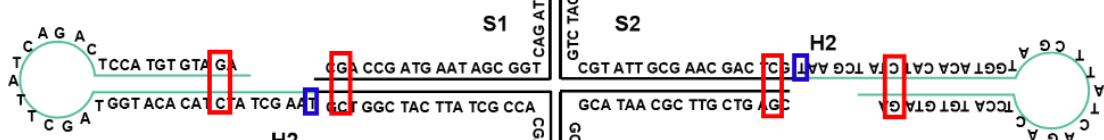
H2 
C

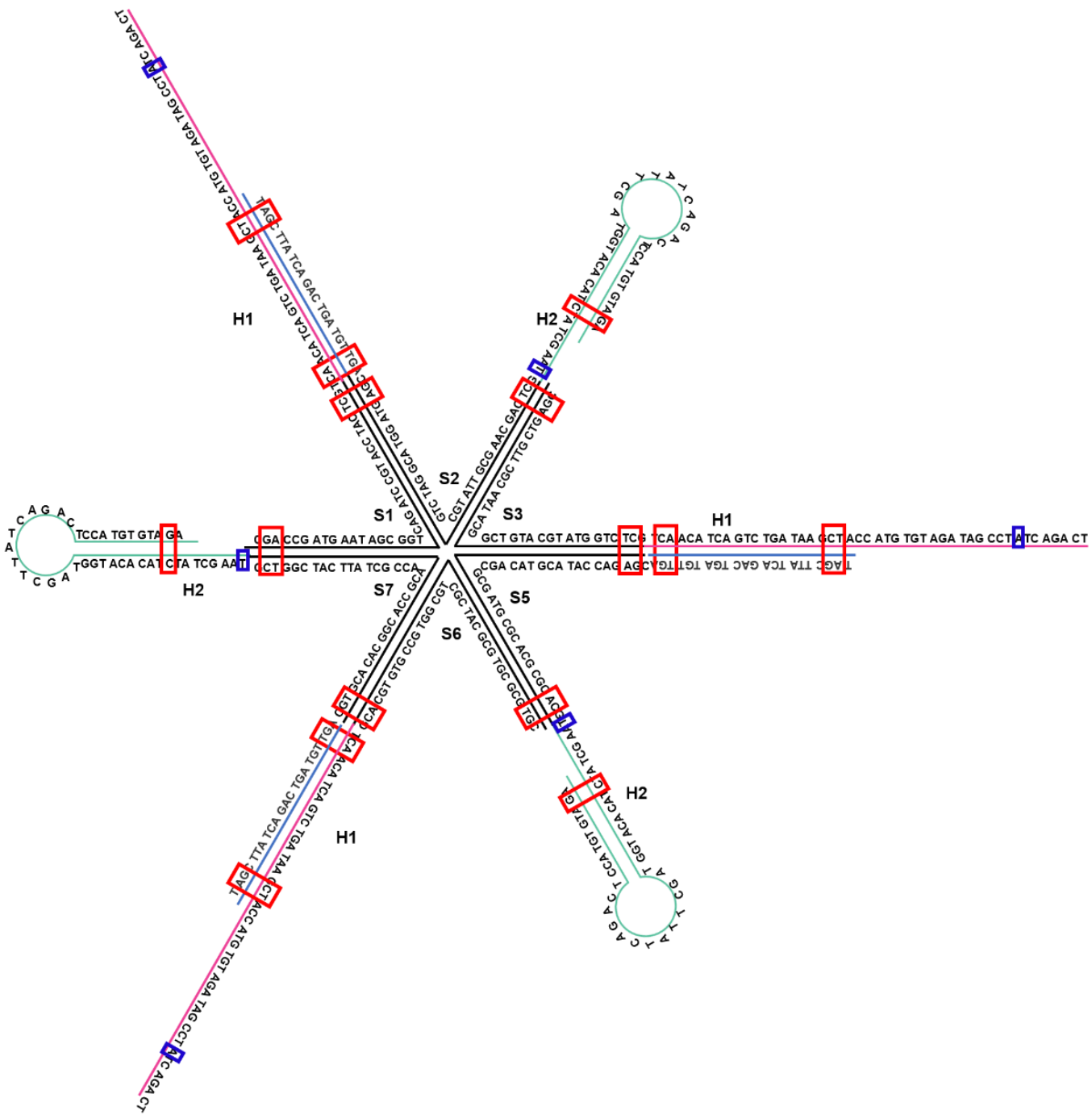

Figure S4. Mutual trap applying base pair information (red boxes) and standard base for measurement of distance between $\mathrm{H} 1$ and $\mathrm{H} 2$ (blue boxes) in (a) D-DNA (b) T-DNA (c) HDNA. 
a

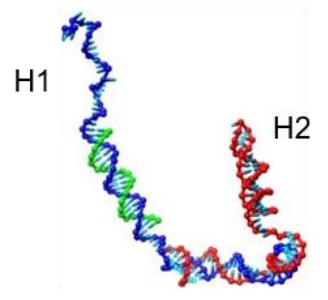

b

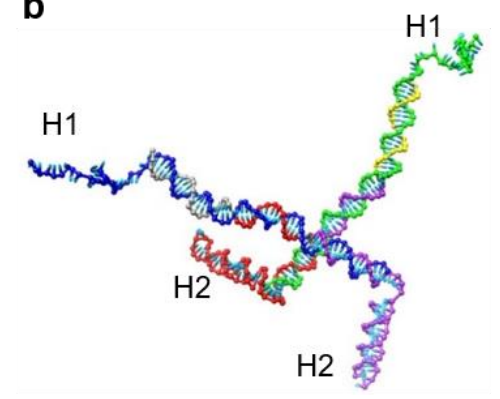

C

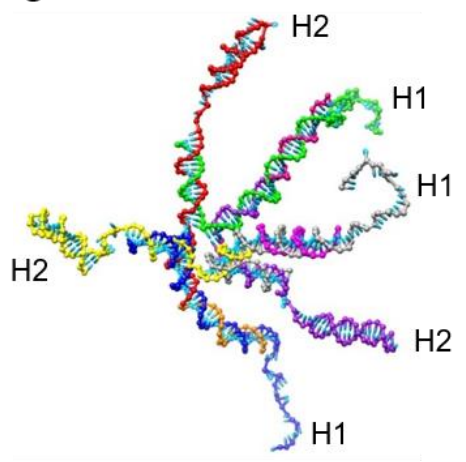

Figure S5. Graphical representation of (a) D-DNA (b) T-DNA (c) H-DNA generated by oxDNA. 


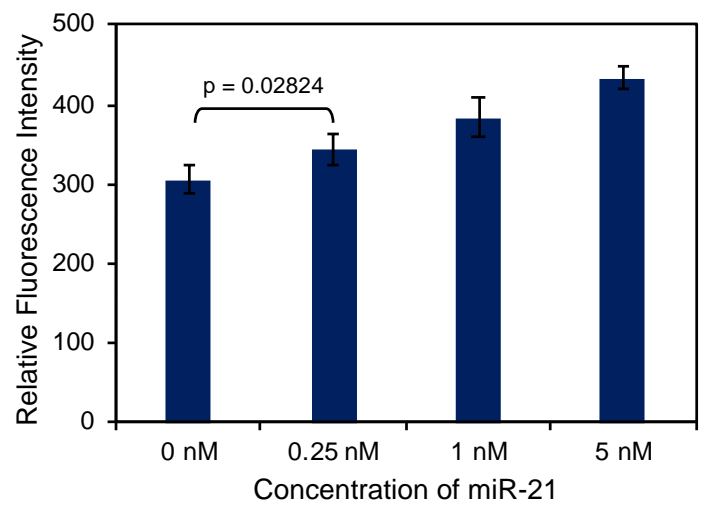

Figure S6. Statistical validation of low LoD of 2-Arm T-DNA. D-DNA and 2-Arm T-DNA were used to remove decreased intermolecular interactions due to localization of $\mathrm{H} 1$ and $\mathrm{H} 2$. For the continuity of the experiment, the miR-21 concentration gradient was used identically, and LoD of $0.25 \mathrm{nM}$ was calculated according to the calculation formula. We do not expect any serious deficiency with mathematical logics, but we also totally agree that there may be inadequate aspects of claiming $0.25 \mathrm{nM}$ of LoD with experiments of $10 \mathrm{nM}$ concentration minimum. In order to overcome this inadequacy and ensure the validity of our experimental results, we conducted additional experiments. The statistical significance of the presented LoD values was reaffirmed by treating the target concentrations with $0 \mathrm{nM}, 0.25 \mathrm{nM}, 1 \mathrm{nM}$ and 5 $\mathrm{nM}$, and compared the fluorescence intensities after 24 hours incubation. The number of samples was fixed at 10, and statistical significance was verified by one-tailed t-test. The result is shown below. Between the blank samples and the $0.25 \mathrm{nM}$ target concentration samples, we have significant $\mathrm{p}$ value $(\mathrm{p}=0.02824)$. The $\mathrm{p}$ values more decreases in comparison with $1 \mathrm{nM}$ and $5 \mathrm{nM}$ samples; $\mathrm{p}=0.001459$ and $\mathrm{p}=0.0000008133$, respectively. This result directly indicates that the 2-Arm T-DNA has significantly high sensitivity. 